\title{
Hormigonado en invierno
}

\section{Introducción}

No hay nada intrínsecamente difícil o peligroso para hormigonar en invierno y no es necesaria ninguna práctica especial. Una vez que se conoce el efecto de las bajas temperaturas sobre el endurecimiento del hormigón, unas cuantas sencillas precauciones protegerán el hormigón inmaduro y permitirán que continúe el hormigonado aun en un pésimo invierno. Para el hormigón el invierno empieza cuando la temperatura del ambiente desciende por debajo de los $5^{\circ} \mathrm{C}$; cuanto más frío hace, más tiempo tarda el hormigón en endurecer Desde un punto de vista muy realista, el hormigón no protegido puede alcanzar un grado de destrucción por el frío, ya que las temperaturas glaciares pueden crear un daño permanente.

Este esquema mural sobre las precauciones a adoptar para el hormigonado en invierno, en forma de sencillos diagramas, es de gran utilidad tratándose de casos normales. Los diagramas pueden emplearse para hacer una estimación de cuál es la protección necesaria para evitar la congelación prematura del hormigón, pero debe tomarse su temperatura después, con el fin de comprobar que la protección era lo bastante buena y para calcular su madurez. Por lo tanto, este esquema mural debe emplearse conjuntamente con el libro de consulta "Winter Concreting", de la Cement and Concrete Association.

\section{Protección del hormigón contra las heladas tempranas}

El agua expansiona a medida que se transforma en hielo y así, si un hormigón recientemente colocado llega a la congelación puede ser severamente dañado y resultar un material completamente inútil. El hielo puede, incluso, partir el hormigón que ha endurecido, y la resistencia del mismo reducirse hasta en un $50 \%$. La protección es, por tanto, necesaria durante el período inicial crítico hasta que el hormigón ha adquirido suficiente resistencia al hielo.

La resistencia que han de presentar los cubos para que el hormigón sea resistente a la helada debe ser de $5 \mathrm{~N} / \mathrm{mm}^{2}$. Esto es aplicable a todos los hormigones con un contenido de cemento de, al menos, $300 \mathrm{~kg} / \mathrm{m}^{3}$ y sigue siendo válida cuando se utilizan cementos especiales. Si el hormigón se encuentra saturado con agua, esta resistencia es insuficiente.

En invierno, por consiguiente, el hormigón no debe curarse con agua. Las superficies expuestas se cubrirán con lienzos o películas de plástico cuidadosamente solapados y cerrados, que retendrán eficazmente el agua necesaria para la hidratación del cemento. A 
medida que el hormigón fragua y endurece, parte de este agua se combinará con el cemento y tendrá lugar un ligero secado del hormigón. En consecuencia, al no estar el hormigón saturado habrá suficiente hueco para que se expansione el agua libre cuando ésta llegue a congelarse; el peligro de rotura, por tanto, es muy reducido.

\section{Abacos para su utilización in situ}

La publicación de la Cement and Cnocrete Association "Winter Concreting" proporciona todos los detalles relativos a los métodos disponibles para proteger el hormigón de la helada prematura y los medios para poder medir la resistencia del hormigón a la helada. Para su utilización in situ pueden ser de gran valor los gráficos, simplificados para ciertos casos estándar.

En la tabla 1 se facilitan detalles constructivos de casos normales seleccionados, referentes a muros y forjados suspendidos de 100, 150 y $200 \mathrm{~mm}$ de espesor.

\section{Cómo utilizar los ábacos}

Los ábacos se han preparado para hormigones confeccionados con cemento portland corriente o con cemento portland de endurecimiento extrarrápido y con tres distintas resistencias: $21,25,5$ y $30 \mathrm{~N} / \mathrm{mm}^{2}$; siendo éstas las resistencias mínimas a compresión a los 28 días. Existen distintos juegos de ábacos para forjados y muros, y en cada caso, las piezas de 100 y $150 \mathrm{~mm}$ se muestran en el primer grupo de seis ábacos, en tanto las piezas de $200 \mathrm{~mm}$ aparecen en el segundo grupo.

En cada ábaco el eje vertical indica la temperatura del hormigón al verterlo en los encofrados, y en el eje horizontal se encuentran las temperaturas mínimas del aire que cabe esperar Con referencia a la tabla 1, el punto de intersección de las dos líneas nos señala cuál es el aislamiento necesario o si se precisa habilitar un recinto con calefacción. En otro caso, si se sabe cual es el encofrado disponible, el aislamiento y la temperatura mínima del aire que cabe esperar, puede determinarse la temperatura a la que se puede verter el hormigón con seguridad.

\section{Ejemplo}

¿Un hormigón con una resistencia mínima a los 28 días de $25,5 \mathrm{~N} / \mathrm{mm}^{2}$ hecho con cemento portland corriente, puede colocarse en obra con seguridad a una temperatura de $10^{\circ} \mathrm{C}$ en un muro de $200 \mathrm{~mm}$ y con un encofrado de contrachapado si la temperatura nocturna llega a ser de $-5^{\circ} \mathrm{C}$ ?

Según la tabla 1, la clave es blanca. En el ábaco, para un muro de $200 \mathrm{~mm}$, cemento portland normal de $25,5 \mathrm{~N} / \mathrm{mm}^{2}$, no existe zona blanca $\mathrm{y}$, como consecuencia, no se vierte con seguridad este hormigón.

Se vertería con seguridad si se pudiese utilizar cemento ERHP (Cemento portland de endurecimiento extrarrápido), o si se emplease un OPC (cemento portland normal) de 30 $\mathrm{N} / \mathrm{mm}^{2}$.

Nota: Durante la época de tiempo frío la temperatura del hormigón al colocarlo en los encofrados no debe ser inferior a $5^{\circ} \mathbf{C}$. 
En otro caso, indiscutiblemente, si el encofrado se recubriese con un panel aislante adicional de $12 \mathrm{~mm}$ se podría utilizar con seguridad la primera mezcla, como se desprende al ver la tonalidad de la clave para tal aisla miento en la tabla 1 y en el ábaco.

\section{Termómetros}

En vista de que la temperatura es de gran importancia cuando se hormigona en invierno y puesto que se debe saber la temperatura del hormigón colocado, es esencial para poder utilizar los ábacos disponer de un termómetro. Los termómetros de cristal deberán tener una protección metálica.

Los termómetros se utilizarán para saber la temperatura del aire y la del hormigón al verterlo, así como durante el endurecimiento. La temperatura del hormigón que está endureciendo se determinará en la superficie haciendo pequeñas cavidades formadas al encastrar cortos tubos metálicos en el hormigón. Las cavidades se rellenarán con agua o con una solución anticongelante para poder hacer las lecturas de las temperaturas con rapidez y exactitud.

Advertencia: Antes de de que el hormigón quede expuesto a temperaturas de congelación se vaciarán las cavidades y se rellenarán o taponarán para evitar el posible almacenamiento de agua.

Los termómetros con protección de latón o los de tipo industrial con esfera y tubo extensible pueden adquirirse en las siguientes firmas:

Engineering Laboratory Equipment Ltd.

RICKMANSWORTH, Herts.

Telephone Rickmansworth 74251.

A. Gallenkamp \& Co. Ltd.

6 Christopher Street.

LONDON EC2. Telephone 01-247 3211.

Negretti \& Zambra Ltd.

Industrial Instruments.

15 New Bond Street.

London W1. Telephone 01-499 3014.

British Rototherm Co. Ltd.

Merton Abbey.

London SW19. Telephone 01-542 7661.

\section{Equipo general para construir en invierno}

Una detallada información sobre precios aproximados de medios tales como paja y otras capas aislantes, calentadores de recintos, capas protectoras, etc. puede encontrarse en la Buyers Guide to Winter Building Equipment (Guía del comprador de equipo para cons- 
trucción en invierno), publicado por The National Federation of Building Trade Employers (Federación Nacional de Representantes de Comercio de la Construcción), (en colaboración con el Ministerio de Obras Públicas y Trabajo), y a la venta en la Asociación de Maestos Constructores de Londres, 47 Bedford Square, London WC1. Telephone 01-636 3891.

\section{Resistencia del hormión y tipo de cemento}

Los ábacos hacen patente el hecho de que los hormigones más resistentes presentan indiscutibles ventajas en invierno como consecuencia de que, si se observa, las zonas oblicuamente rayadas (en las cuales se precisan cubiertas calentadas) son más reducidas a medida que la resistencia del hormigón aumenta. Optar por un hormigón más resistente es, por consiguiente, una manera de proteger el hormigón contra las bajas temperaturas. Para una misma docilidad, e incrementando el contenido de cemento de la mezcla, se tiene la ventaja adicional de aumentar el margen de seguridad contra una inesperada caída de la temperatura del aire.

De una forma similar los hormigones a base de cemento portland de endurecimiento rápido o de cemento extrarrápido (en invierno es preferible el último, puesto que contiene una correcta adición de mezcla acelerante, uniformemente repartida en el cemento) presentan la ventaja de que al acelerar el proceso de hidratación se eleva la temperatura del hormigón durante el crítico período inicial. Si no se dispone de un cemento portland de endurecimiento extrarrápido, puede utilizarse en el hormigón armado un aditivo tal como el cloruro cálcico (anhidro) dosificado a razón de un 1,5\% por peso de cemento. En el hormigón pretensado no debe utilizarse ni cloruro cálcico ni cemento portland de endurecimiento extrarrápido. Es preciso tener gran cuidado cuando se utilizan aditivos aceleradores. Ningún aditivo comunica al hormigón propiedades "anticongelantes".

Advertencia: Detalles completos sobre limitaciones en la utilización del cemento portland de endurecimiento extrarrápido y aditivos acelerantes, se pueden encontrar en el Manual de la Asociación titulado "Hormigonado en invierno". También deben confrontarse las especificaciones de obra.

\section{Retirada de los encofrados}

En condiciones invernales es necesario adoptar precauciones antes de desencofrar y, particularmente, antes de retirar los apoyos de los encofrados tales como durmientes y virotillos de las placas y vigas. El único sistema realmente garantizado para saber cuando se puede desencofrar con seguridad es registrar las temperaturas en la superficie o cerca de la superficie del hormigón que se halla en período de endurecimiento, y realizar esta medida en la parte más expuesta. Este registro de temperaturas puede servir para comprobar si el hormigón ha alcanzado su nivel de resistencias contra el hielo. Esto ocurre cuando su resistencia a la compresión es de, por lo menos, $5 \mathrm{~N} / \mathrm{mm}^{2}$. Una explicación completa puede encontrarse en "Winter Concreting" (Hormigonado en invierno). En esta etapa pueden retirarse los costeros de las piezas que no soportan cargas, tales como vigas, muros y columnas. Si los citados costeros no precisan ser utilizados inmediatamente es preferible dejarlos en su sitio, ya que así se acelera el proceso de endurecimiento y se reduce el tiempo para retirar los encofrados que soportan cargas, tales como durmientes y puntales. 
Aunque en esta etapa el hormigón, caso de no estar saturado de agua, puede resistir temperaturas de congelación, con cierta antelación debe ser suficientemente resistente para que pueda soportar cargas, incluido su propio peso, en losas y vigas. Al mismo tiempo que se siguen registrando las temperaturas del hormigón, debe hacerse de vez en cuando una valoración aproximada de sus resistencias. Cuando dicha valoración - determinada preferentemente sobre cubos colocados a pie de obra - alcanza el mínimo especificado, pueden retirarse los elementos sustentantes del encofrado. La resistencia mínima especificada debe determinarse para cada caso y habrá que tener en cuenta un coeficiente de seguridad, comprendido, generalmente, entre 2 y 3.

La figura 1 muestra la resistencia a la compresión de los cubos en función de la madurez (expresada como una cantidad de tiempo para diversas temperaturas) de un hormigón típico de resistencia media. Deberá usarse como guía, únicamente, para el probable desarrollo de resistencias en el hormigón. La resistencia real se determinará ensayando cubos almacenados bajo condiciones lo más parecidas posibles a las de la obra.

Fig. 1.-Desarrollo típico de las resistencias en el homigón utilizando cementos: ordinario, rápido y extrarrápido.

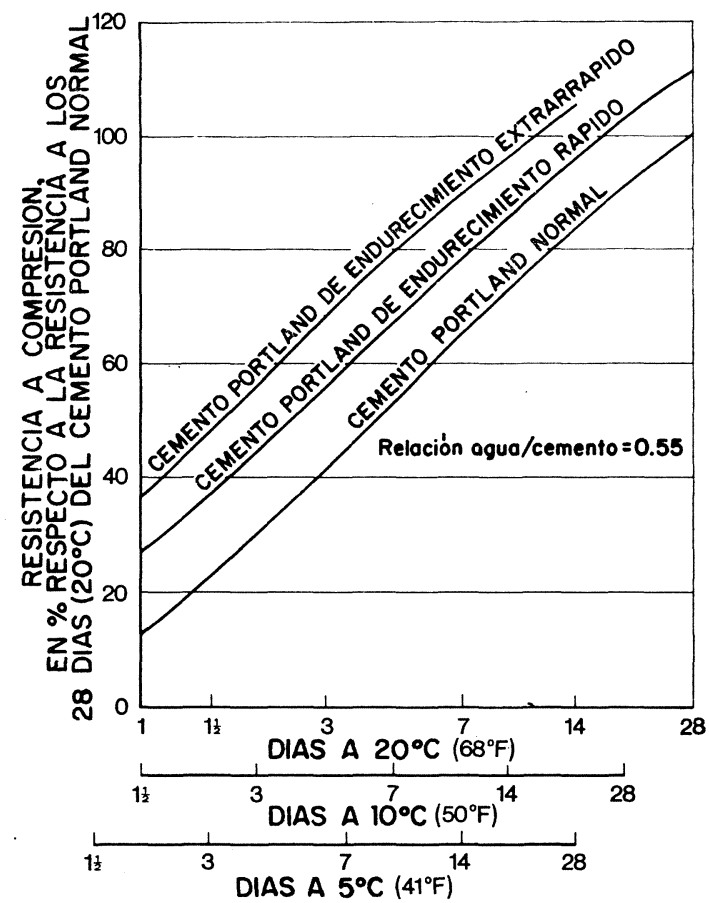

Cuando la resistencia del hormigón endurecido no se conoce, es decir, cuando no se anotan las temperaturas ni se ensayan los cubos dispuestos in situ, puede emplearse la tabla 2, como regla general para determinar el tiempo de desencofrar, siempre que se trate de un hormigón de buena calidad que pueda, por lo menos, sustentar su propio peso. Los días en los que la temperatura del ambiente caíga por debajo de $0^{\circ} \mathrm{C}$, no se contabilizarán para el total.

La tabla 2 no indica los tiempos para desencofrar los costeros, debido a que dichos tiempos dependen de una forma muy crítica de la temperatura del hormigón que está endureciendo. Cuando no se realizan tales determinaciones, pero se sabe que la temperatura del hormigón no ha llegado a ser inferior a $\operatorname{los} 5^{\circ} \mathrm{C}$, se mantendrán los costeros en posición durante 3 días si se trata de cemento portland normal, y aproximadamente la mitad de este tiempo para un cemento portland de endurecimiento extrarrápido.

En todo caso siempre es más seguro, y más económico, colocar registradores, que se utilizarán para comprobar que el hormigón ha alcanzado su adecuado nivel de resistencia al hielo. 
T A B L A 1

\begin{tabular}{|c|c|c|c|}
\hline Clave & Cemento & $\begin{array}{l}\text { Espesor } \\
(\mathbf{m m})\end{array}$ & Encofrado y aislamiento \\
\hline & \multirow[t]{2}{*}{ SUELOS } & 100 & $\begin{array}{l}\text { ARRIBA: Lienzo alquitranado sobre esterilla de } \\
\text { paja de } 50 \mathrm{~mm} \text {. } \\
\text { ABAJO: Contrachapado de } 20 \mathrm{~mm}+\text { cartón ais- } \\
\text { lante de } 12 \mathrm{~mm} \text {. }\end{array}$ \\
\hline & & 150 a 200 & $\begin{array}{l}\text { ARRIBA : Lienzo alquitranado con cámara de aire } \\
\text { de } 50 \mathrm{~mm} \text {. } \\
\text { ABAJO: Contrachapado de } 50 \mathrm{~mm} \text {. }\end{array}$ \\
\hline & \multirow[t]{2}{*}{ MUROS } & 100 & Contrachapado de $20 \mathrm{~mm}$ + cartón aislante. \\
\hline & & \multicolumn{2}{|c|}{$\begin{array}{l}\text { Se señala el límite para los muros de } 150 \mathrm{~mm} \text { en los encofrados } \\
\text { de contrachapado de } 20 \mathrm{~mm} \text {. }\end{array}$} \\
\hline \multirow[t]{2}{*}{$\Leftrightarrow$} & \multirow[t]{2}{*}{ SUELOS } & 100 & $\begin{array}{l}\text { ARRIBA: Lienzo alquitranado sobre } 25 \mathrm{~mm} \text { de fi- } \\
\text { bra de vidrio o lana mineral. } \\
\text { ABAJO: Contrachapado de } 20 \mathrm{~mm}+\text { poliestireno } \\
\text { dilatado de } 12 \mathrm{~mm} \text {. }\end{array}$ \\
\hline & & 150 a 200 & $\begin{array}{l}\text { ARRIBA: Lienzo alquitranado sobre esterilla de } \\
\text { paja de } 50 \mathrm{~mm} \text {. } \\
\text { ABAJO: } 20 \mathrm{~mm} \text { de contrachapado }+12 \mathrm{~mm} \text { de } \\
\text { cartón aislante. }\end{array}$ \\
\hline \multirow[t]{2}{*}{ 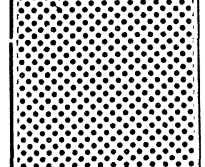 } & \multirow[t]{2}{*}{ MUROS } & 100 & Papel metálico $+25 \mathrm{~mm}$ de poliestireno dilatado. \\
\hline & & 150 a 200 & $\begin{array}{l}\text { Contrachapado de } 20 \mathrm{~mm}+12 \mathrm{~mm} \text { de cartón } \\
\text { aislante. }\end{array}$ \\
\hline \multirow{3}{*}{ 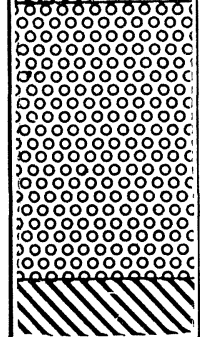 } & SUELOS & 150 a 200 & $\begin{array}{l}\text { ARRIBA: Lienzo alquitranado sobre } 25 \mathrm{~mm} \text { de } \\
\text { fibra de vidrio o lana mineral. } \\
\text { ABAJO: Contrachapado de } 20 \mathrm{~mm}+12 \mathrm{~mm} \text { de } \\
\text { poliestireno dilatado. }\end{array}$ \\
\hline & MUROS & 150 a 200 & Papel metálico $+25 \mathrm{~mm}$ de poliestireno dilatado. \\
\hline & & & Cerramiento con calefacción. \\
\hline
\end{tabular}

NO T A S:

1. En lugar de los encofrados de contrachapado de $20 \mathrm{~mm}$ puede emplearse molde de papel metálico $+12 \mathrm{~mm}$ de poliestireno dilatado.

2. Si la disposición de los elementos de sustentación de la parte inferior es tal que no resulta conveniente añadir un aislamiento al encofrado de dicha parte inferior, ésta se apantallará y la temperatura del recinto se mantendrá por encima del punto de congelación.

3. Equivalencia entre unidades métricas y pulgadas:

$\begin{array}{lrrrrrrr}\mathrm{mm} & 12 & 20 & 25 & 50 & 100 & 150 & 200 \\ \text { in. } & 1 / 2 & 3 / 4 & 1 & 2 & 4 & 6 & 8\end{array}$




\section{MUROS de 100 a $150 \mathrm{~mm}$ de espesor}

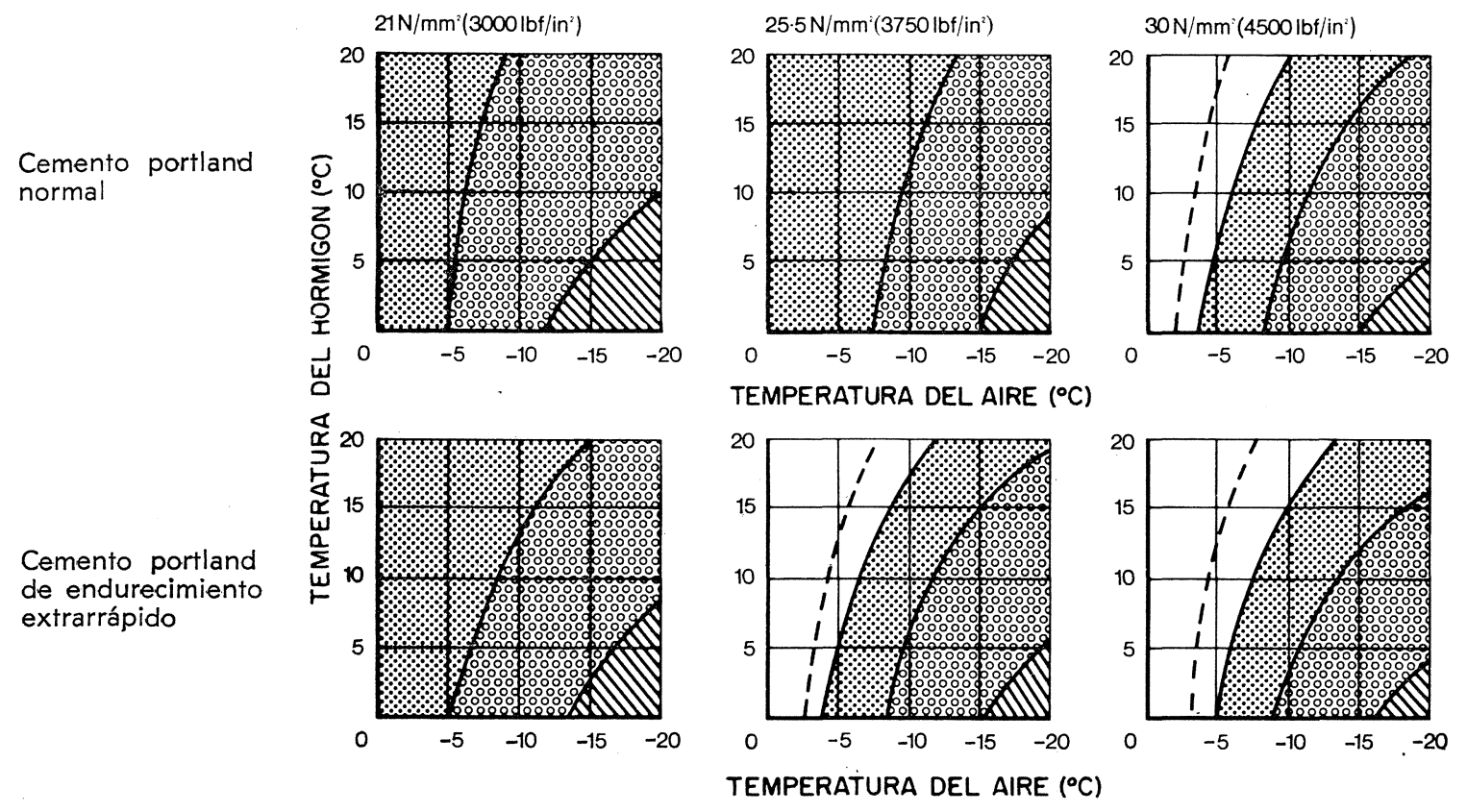

MUROS de $200 \mathrm{~mm}$ de espesor

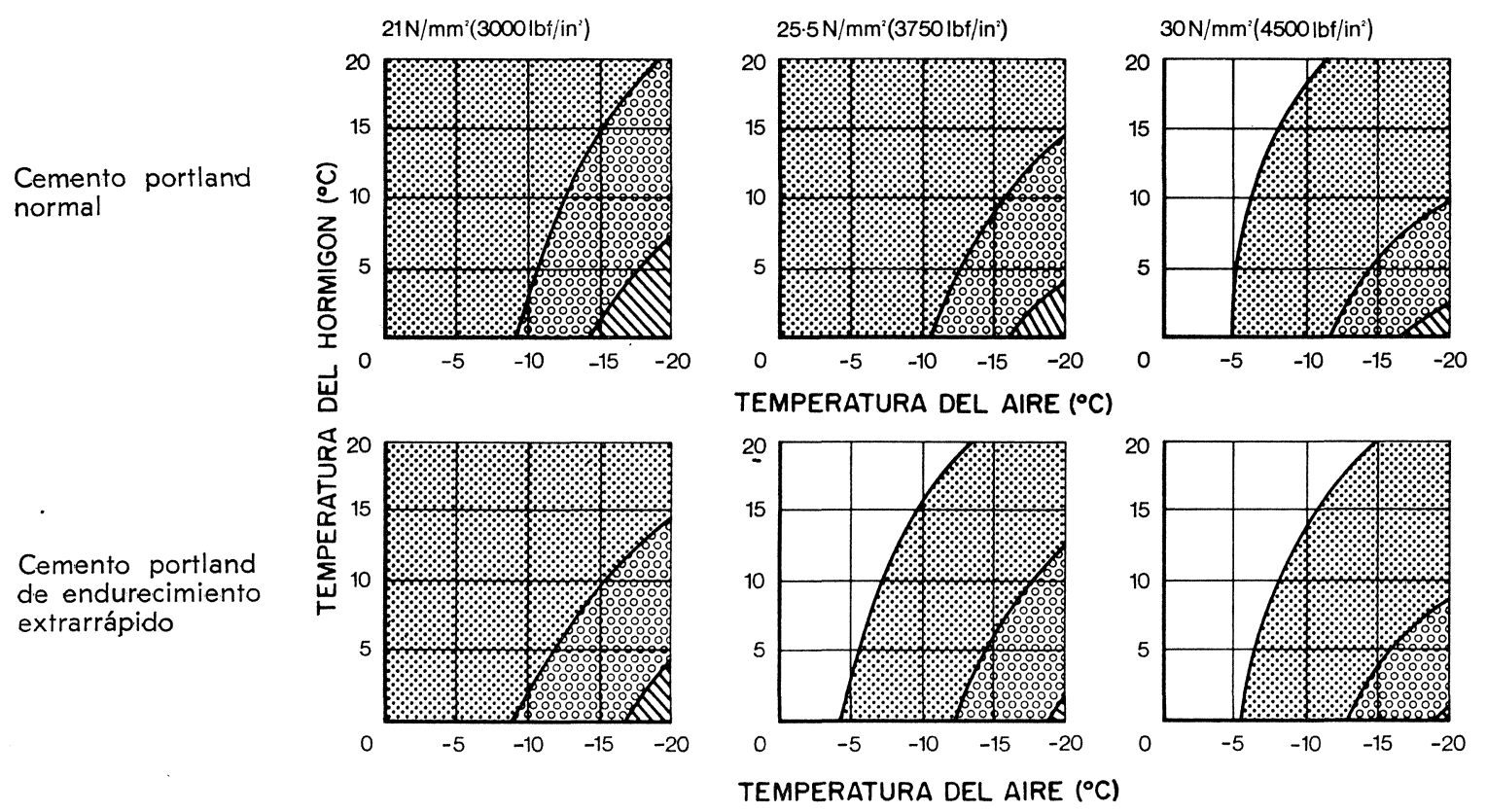

NB En invierno la temperatura del hormigón no debe ser inferior a $5^{\circ} \mathrm{C}$ 

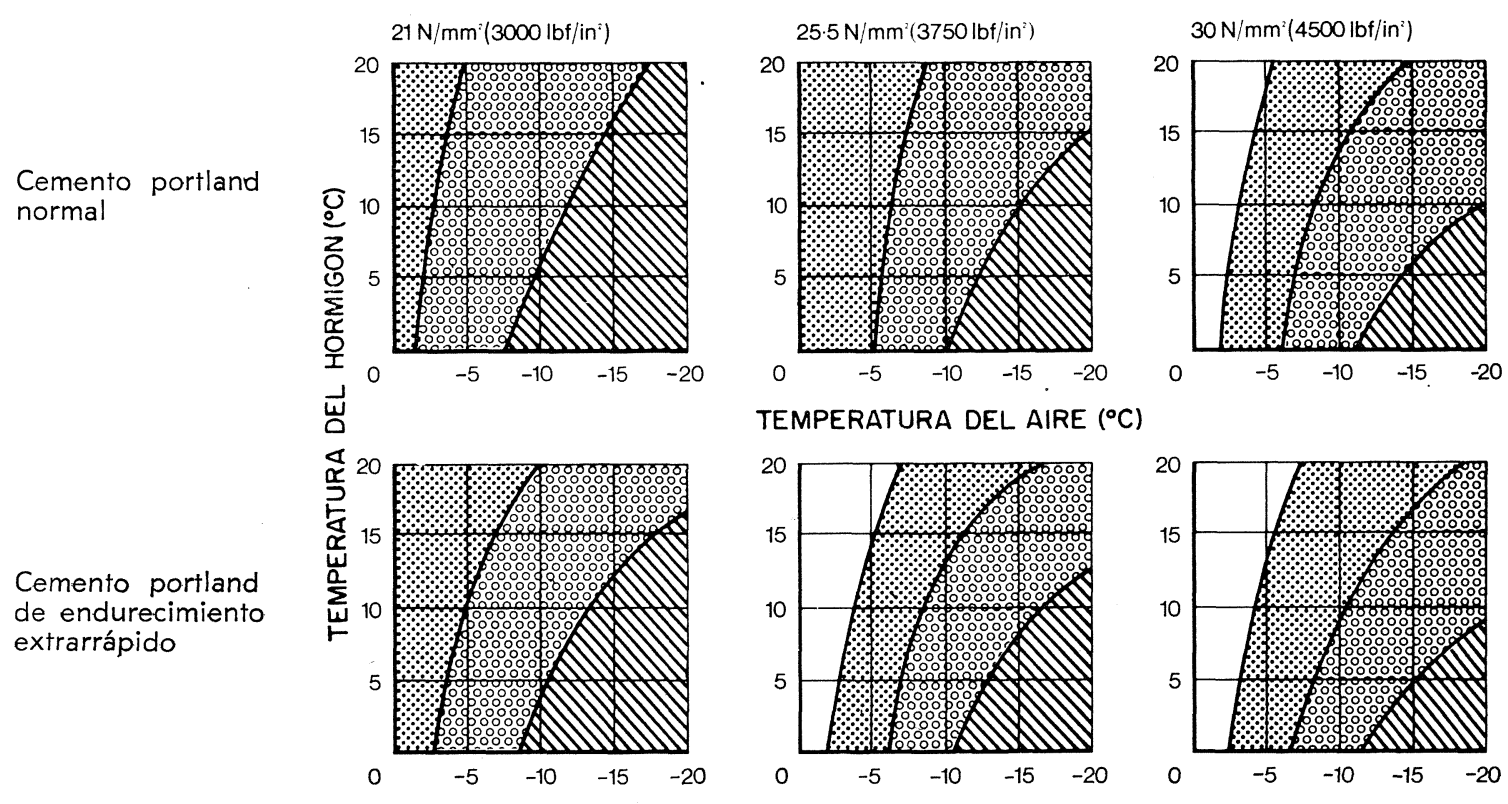

TEMPERATURA DEL AIRE $\left({ }^{\circ} \mathrm{C}\right)$
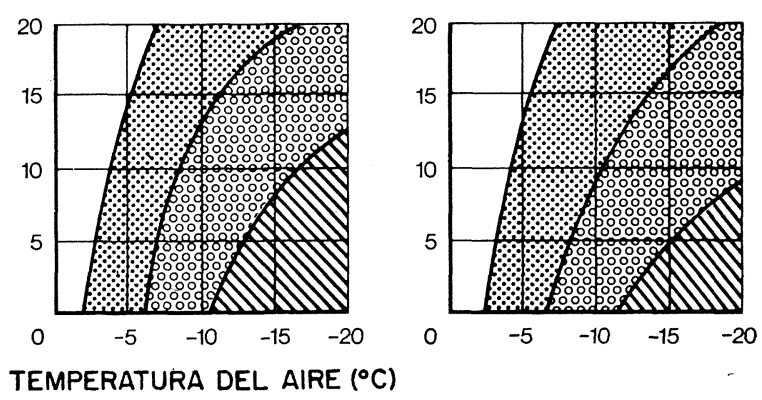

FORJADOS de $200 \mathrm{~mm}$ de espesor
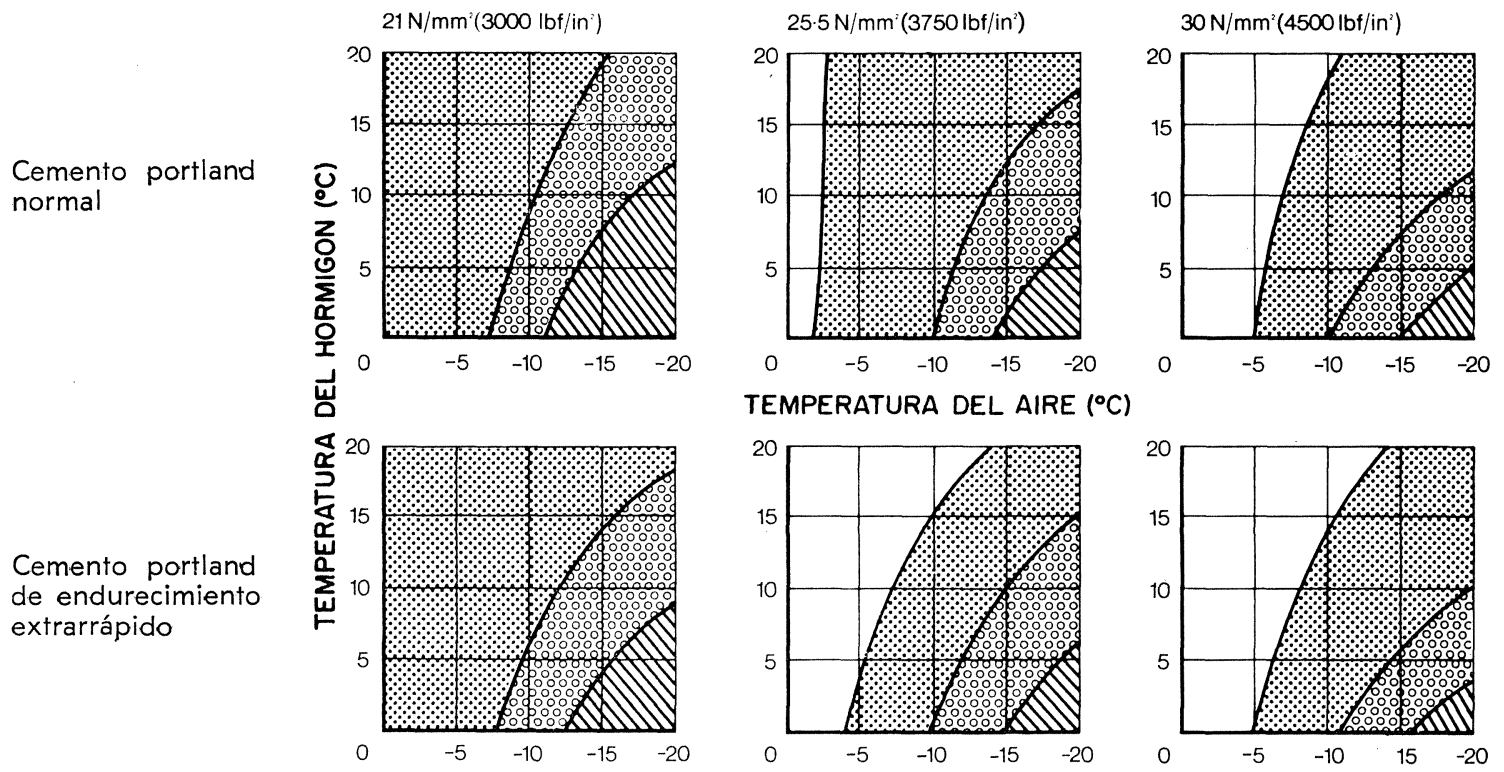

TEMPERATURA DEL AIRE $\left({ }^{\circ} \mathrm{C}\right)$
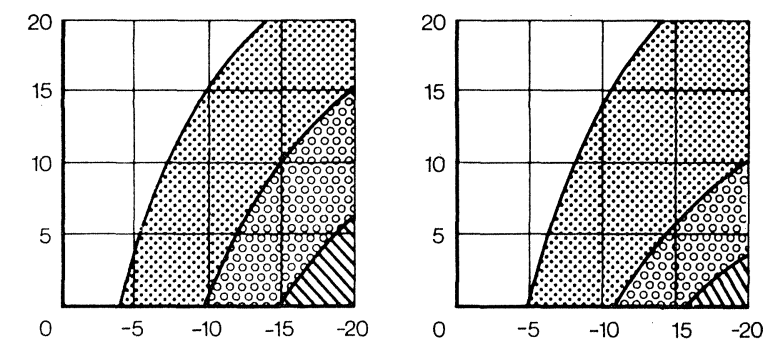

TEMPERATURA DEL AIRE $\left({ }^{\circ} \mathrm{C}\right)$

NB En invierno la temperatura ambiente no debe ser inferior a $5^{\circ} \mathrm{C}$ 
TAB L A 2

Tiempos mínimos recomendados para desencofrar, cuando el elemento soporta únicamente su propio peso. Si existen dudas, siempre se optará por un tiempo más prolongado

\begin{tabular}{|c|c|c|c|c|c|}
\hline \multirow{2}{*}{$\begin{array}{c}\text { Tipo de cemento } \\
\text { utilizado }\end{array}$} & \multirow[b]{2}{*}{ Clima } & \multicolumn{4}{|c|}{ Tiempo minimo, en días, para: } \\
\hline & & $\begin{array}{c}\text { Placas } \\
\text { (con puntales) }\end{array}$ & $\begin{array}{l}\text { Arriba de vigas } \\
\text { (con puntales) }\end{array}$ & $\begin{array}{l}\text { Puntales para } \\
\text { las placas }\end{array}$ & $\begin{array}{c}\text { Puntales para } \\
\text { las vigas }\end{array}$ \\
\hline Portland normal & $\begin{array}{l}\text { frío } \\
\text { normal }\end{array}$ & $\begin{array}{l}7 \\
31 / 2\end{array}$ & $\begin{array}{r}14 \\
7\end{array}$ & $\begin{array}{r}14 \\
7\end{array}$ & $\begin{array}{l}28 \\
14\end{array}$ \\
\hline $\begin{array}{l}\text { Portland de endureci- } \\
\text { miento rápido }\end{array}$ & $\begin{array}{l}\text { frío } \\
\text { normal }\end{array}$ & $\begin{array}{l}4 \\
2\end{array}$ & $\begin{array}{l}8 \\
4\end{array}$ & $\begin{array}{l}8 \\
4\end{array}$ & $\begin{array}{l}16 \\
8\end{array}$ \\
\hline $\begin{array}{l}\text { Portland de endureci- } \\
\text { miento extrarrápido }\end{array}$ & $\begin{array}{l}\text { fío } \\
\text { normal }\end{array}$ & $\begin{array}{l}3 \\
11 / 2\end{array}$ & $\begin{array}{l}6 \\
3\end{array}$ & $\begin{array}{l}6 \\
3\end{array}$ & $\begin{array}{r}12 \\
6\end{array}$ \\
\hline
\end{tabular}

Tiempo frío $=$ temperatura del aire: alrededor de $3^{\circ} \mathrm{C}$.

Tiempo normal $=$ temperatura del aire: alrededor de $16^{\circ} \mathrm{C}$. 